\title{
Harmonic Mitigation In Grid-Tied TPSPPS Via Novel PRESH Controller
}

\author{
Uma Yadav $^{1 *}$, Anju Gupta ${ }^{2}$, Rajesh Kr Ahuja ${ }^{3}$ \\ ${ }^{12,3}$ Department of Electrical Engineering, J C Bose University of Science and Technology YMCA \\ Faridabad-, India \\ *er.yadavuma11@gmail.com,19001903004@jcboseust.ac.in
}

Received: June 15, 2021. Revised: November 12, 2021. Accepted: December 7, 2021. Published: December 26, 2021.

\begin{abstract}
The proposed paper deals with a new type of controller credited with a name of "Novel PRESH" helpful in mitigating the harmonic of Grid Tied TPSPPS (GridTied Three Phase Solar Photovoltaic Power System) even during abnormal grid condition. Novel PRESH controller is formed by combining the characteristic of PRES and RESH Controller and its harmonic mitigation analysis is done with the help of both Bode-Plot and MATLAB Simulink. Presently, for eliminating the harmonic from Grid -Tied TPSPPS, various filters and controllers have already been proposed but it either resulted in increase of computational load or make the system bulky. Earlier technique develops in eliminating the harmonic face difficulty in eliminating the harmonic when the reference waveform get distorted from its original position. The proposed "Novel PRESH" controller can also be incorporated when grid suffers from any abnormal condition. The presented paper will also discuss the performance analysis of controller along with its design procedure that are helpful in mitigating the THD of three phase SPPS near to $1 \%$ and thus satisfying the IEEE standard 519 and 1547.
\end{abstract}

Keywords-GTSPPS, PRES, PRESH, RESH, THD.

\section{INTRODUCTION}

$\mathrm{S}_{\mathrm{ic}}^{\mathrm{o}}$ lar Photovoltaic Power System (SPPS) can be connected $S_{\text {to }}$ grid using converter [1]-[8]. The converter used here will ensure flow of power from SPPS to grid. SPPS can also be connected with other local load, energy storage [9]-[11]. The power quality of grid mainly depends upon voltage, frequency, harmonic, etc [12]-[14]. In order to have good power-factor and minimum line losses the harmonic content of grid connected solar photovoltaic system should be as low as to $1 \%$.

Photo-Voltaic system should have low current harmonic distortion so that all other equipments connected to grid do not face any adverse effects. Acc. to IEEE standard 519 and 1547, THD (Total Harmonic Distortion) is kept below 5\% [15]. Generally, for reducing current harmonic of SPPS, earlier technique developed for eliminating the harmonics are through: lead-lag [16], modified PI [17]-[18], repetitive [19][20], dead-beat [21], PR controller [22]-[24], shunt filter [25][29], PRES Controller [30]-[35].

Common technique adopted before for eliminating harmonics among researcher was to make use of resonant current controller [22]-[23]. This controller makes use of proportional resonant and resonant compensator. The function of duo is to keep track of fundamental reference current signal and for attenuating the current harmonics. With normal condition, this controller as referred in reference [23]-[24] work perfectly, but when abnormal condition arises, this compensator performance deteriorates resulting in increase of current harmonic distortion.

The simplest technique for eliminating the current harmonic is by engaging the PRES because of its modularity. In PRES controller, $\mathrm{K}_{\mathrm{P}}$ (Proportional gain) is added with resonant path which is set at desired frequency.

Several advanced techniques for mitigating the harmonic have been discussed in details [36]-[41]. These control techniques make use of separately generated current reference by the help of positive and negative sequence component. Phase locked loop Algorithm as discussed in [30] and [39]-[40] does not get affect from the voltage harmonic, inter-harmonic and imbalance conditions. But these control techniques are complex and have high computational loading problem. The alternative for these techniques is achieved through [42]-[44] where Resonant Harmonic Controller is incorporated in series with Proportional resonant controller instead of connecting in parallel configuration.

This paper at first step discuss the design procedure of Novel PRESH controller.

In second step, performance analysis of Novel PRESH controller will be seen. For eliminating the higher order harmonic, PRES compensator is connected in parallel with RESH controller to make a Novel PRESH controller instead of conventional series connection as discussed in [41]-[42]. The analysis of both controller is done through the help of graph along with bode plot analysis. 
The main advantage of Novel PRESH controller proposed in this paper is to show that even if reference waveform is distorted one, this controller can tackle it in a very reliable manner and that is one of the originality of this proposed paper.

Novelty and Originality of the proposed research paper are as:

- Earlier technique develop for reducing current harmonics among researcher were lag-lead controller [16], modified PI controller [17]-[18], repetitive controller [19]-[20], dead beat controller [21], PR controller [22]-[23], shunt filter [24]-[28], suffer certain drawback as indicated:

- Standard PI controller, can't track ac current reference.

- [17]-[18], shows very poor response in tracking sinusoidal reference as well as while rejecting the disturbances.

- [22]-[23] can't use with present day Grid Connection as there is need of digital implementation of controller for rejecting the harmonic.

- Elimination of harmonic through the use of shunt filter becomes an old technique as their inability in eliminating the harmonic as per IEEE reference 519 and 1547.

- Design algorithm of Novel PRESH (Proportional Resonant Harmonic) controller is discussed where PRES controller is connected in parallel with RESH (Resonant Harmonic) controller instead of conventional series connection.

- Performance Analysis of Novel PRESH controller is discussed in term of harmonic mitigation with low computational load as compared to standard controller design.

The proposed paper is carved out in the following manner: Section II will discuss about three phase grid tied solar photovoltaic power system (SPPS), Section III will deal with design algorithm of Novel PRESH controller, Section IV will deal with performance analysis of Novel PRESH controller in term of Bode-Plot analysis and harmonic mitigation.

\section{GRID-TIED THREE PHASE SPPS}

Fig.1 represent the grid-tied three phase SPPS having Photovoltaic module/array, a capacitor $\mathrm{C}_{\mathrm{dc}}$ and a 3- phase voltage source inverter connected with three phase grid having voltages as Vga, Vgb and Vgc.

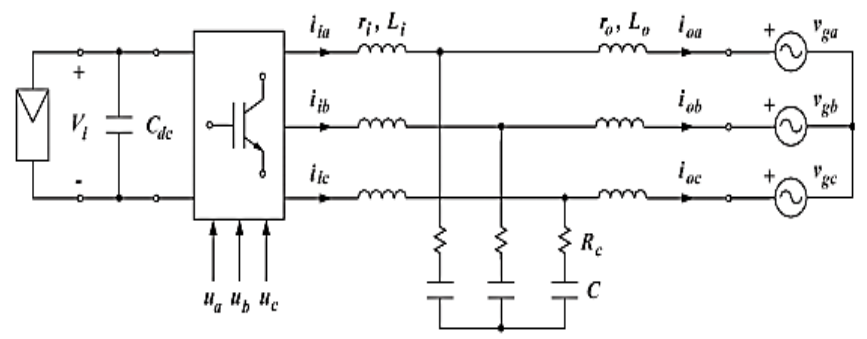

Fig.1 Grid -Tied Three Phase Solar Photovoltaic Power System (TPSPPS)
For reducing the high frequency switching harmonic, L-C-L filter is employed and for attenuating the peak magnitude of L-C-L filter at resonance frequency and damping resistor is made to connect in series with capacitor.

\section{A. Open loop Mode (OLM) of 3-phase Grid-Tied TPSPPS}

Average model of Grid-tied TPSPPS is indicated by Fig. 2. Input to this model is $\mathrm{V}_{\mathrm{i}}$ which is a dc link voltage, grid voltage is denoted as $\mathrm{V}_{\mathrm{g}}$ and control input $\mathrm{d}$ whose value varies from -1 to +1 .

$$
\begin{aligned}
& -1 \leq \mathrm{d}_{\alpha} \leq+1 \\
& -1 \leq \mathrm{d}_{\beta} \leq+1
\end{aligned}
$$

Inverter current is denoted by $\mathrm{i}_{\mathrm{i}}$ and grid current is denoted by $\mathrm{i}_{\mathrm{o}}$.
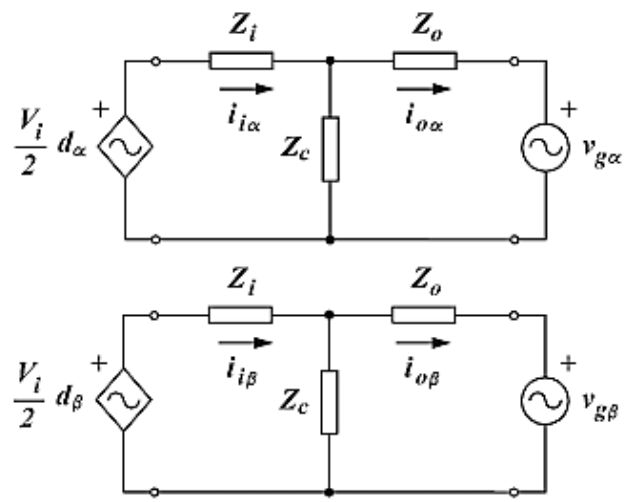

Fig. 2 Average circuit Model of Grid -tied 3-phase SPPS

The parameter used in the transfer function of above compensator is shown by Table 1, along with list of value used in the work. Table 1 also contain the detail parameter of grid tied three phase SPPS used here. 
Table 1 Parameters of Grid -Tied Three Phase SPPS

\begin{tabular}{|l|l|l|}
\hline Symbol & Quantity & Nominal Value \\
\hline $\mathrm{P}_{\mathrm{m}}$ & Maximum output power & $3.2 \mathrm{KW}$ \\
\hline $\mathrm{f}_{\mathrm{i}}$ & Switching frequency & $10 \mathrm{KHz}$ \\
\hline $\mathrm{V}_{\mathrm{i}, \text { oc }}$ & Open Circuit PV array output Voltage & $750 \mathrm{~V}$ \\
\hline $\mathrm{I}_{\mathrm{i}, \mathrm{SC}}$ & Short circuit PV array output current & $5.4 \mathrm{~A}$ \\
\hline $\mathrm{V}_{\mathrm{i}, \mathrm{MP}}$ & Maximum power PV output voltage & $650 \mathrm{~V}$ \\
\hline $\mathrm{I}_{\mathrm{i}, \mathrm{MP}}$ & Maximum Power PV output current & $4.9 \mathrm{~A}$ \\
\hline $\mathrm{L}_{\mathrm{i}}$ & Inverter side Inductance & $6.9 \mathrm{mH}$ \\
\hline $\mathrm{R}_{\mathrm{i}}$ & Inverter side resistance & $0.27 \Omega$ \\
\hline $\mathrm{C}$ & Filter Capacitor & $680 \mathrm{nF}$ \\
\hline $\mathrm{R}_{\mathrm{c}}$ & Filter damping resistance & $6.8^{\prime} \Omega$ \\
\hline $\mathrm{L}_{\mathrm{o}}$ & Grid side inductance & $2.1 \mathrm{mH}$ \\
\hline $\mathrm{R}_{\mathrm{o}}$ & Grid side resistance & $0.14 \Omega$ \\
\hline $\mathrm{V}_{\mathrm{g}}$ & Grid Voltage (rms, phase to neutral) & $200 \mathrm{~V}$ \\
\hline $\mathrm{f}_{\mathrm{o}}$ & Grid frequency & $50 \mathrm{~Hz}$ \\
\hline $\mathrm{K}_{\mathrm{p}}$ & Proportional gain & $60 \Omega$ \\
\hline $\mathrm{K}_{\mathrm{i}}$ & Fundamental integral gain & $300 \Omega \mathrm{s}^{2}$ \\
\hline $\mathrm{K}_{\mathrm{in}}$ & n-harmonic integral gain & $300 \Omega \mathrm{s}^{2}$ \\
\hline$\epsilon_{1}$ & Fundamental damping factor & 0.01 \\
\hline$\epsilon_{\mathrm{n}}$ & n-harmonics damping factor & 0.01 \\
\hline $\mathrm{N}$ & Selected harmonics to be attenuated & $5,7,11,13$ \\
\hline $\mathrm{T}_{\mathrm{d}}$ & Control Processing delay time & $100 \mu \mathrm{s}$ \\
\hline & & \\
\hline
\end{tabular}

\section{DESIGN ALGORITHM OF NOVEL PRESH CONTROLLER}

\section{A. Design Procedure of Novel PRESH controller}

The main purpose of Novel PRESH controller is to achieve lower current harmonic distortion even if grid current experiences the abnormal conditions.

\section{$1^{\text {st }}$ Step: Control Configuration of Novel PRESH controller}

In this proposed Novel PRESH controller, shown by Fig. 3, inverter current is used as input to compensator of lower forward gain instead of applying the difference of reference current signal and grid current.
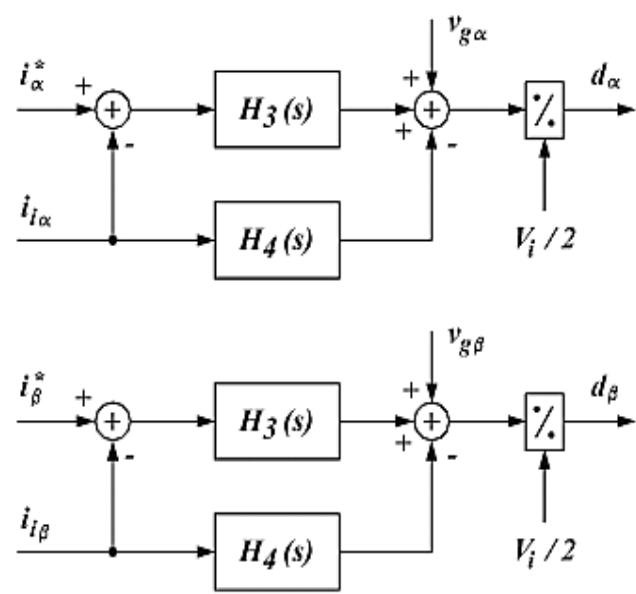

Fig. 3 Proposed Novel PRESH Controller
Where, $\mathrm{H}_{3}(\mathrm{~s})$ is PRES (Proportional Resonant) controller and $\mathrm{H}_{4}(\mathrm{~s})$ is RESH (Resonant Harmonic) Controller.

Transfer functions of Novel PRESH controller are obtained as:

$$
\begin{gathered}
H_{3}(s)=\frac{k_{i 1} 2 \xi_{1} \omega_{o} s}{s^{2}+2 \xi_{1} \omega_{o} s+\omega_{o}^{2}} \\
H_{4}(s)=k_{p}+\sum_{n} \frac{k_{i n} 2 \xi_{n}\left(n \omega_{o}\right) s}{s^{2}+2 \xi_{n}\left(n \omega_{o}\right) s+\left(n \omega_{o}\right)^{2}}
\end{gathered}
$$

\section{$2^{\text {nd }}$ Step: Closed-Loop Transfer Function of Novel PRESH controller}

From Fig. 3, control input of proposed Novel PRESH controller can be written as

$$
\begin{aligned}
& d_{\alpha}=\frac{2}{V_{i}}\left[v_{g \alpha}+H_{3}(s)\left(i_{\alpha}^{*}-i_{i \alpha}\right)-H_{4}(s) i_{i \alpha}\right] H_{d}(s) \\
& d_{\beta}=\frac{2}{V_{i}}\left[v_{g \beta}+H_{3}(s)\left(i_{\beta}^{*}-i_{i \beta}\right)-H_{4}(s) i_{i \beta}\right] H_{d}(s)
\end{aligned}
$$

By substituting equation (5) and (6) in Fig. 2 so as to obtain closed loop transfer function of proposed Novel PRESH controller, we get:

$$
\begin{gathered}
T(s)=\left(Z_{c}(s)+Z_{o}(s)\right) G_{i}(s)\left(H_{3}(s)+H_{4}(s)\right) \\
\times H_{d}(s) \\
G_{r}(s)=\frac{Z_{c}(s) G_{i}(s) H_{3}(s) H_{d}(s)}{1+T(s)} \\
G_{g}(s)=-\frac{G_{i}(s)\left(Z_{i}(s)+\left(H_{3}(s)+H_{4}(s)\right) H_{d}(s)\right)}{1+T(s)}
\end{gathered}
$$

\section{ANALYSIS OF NOVEL PRESH CONTROLLER}

\section{A. Bode Plot Analysis of proposed Novel PRESH} Controller

Bode Plot figure of PRES and RESH controller used in proposed Novel PRESH Controller is indicated by Fig. 4.

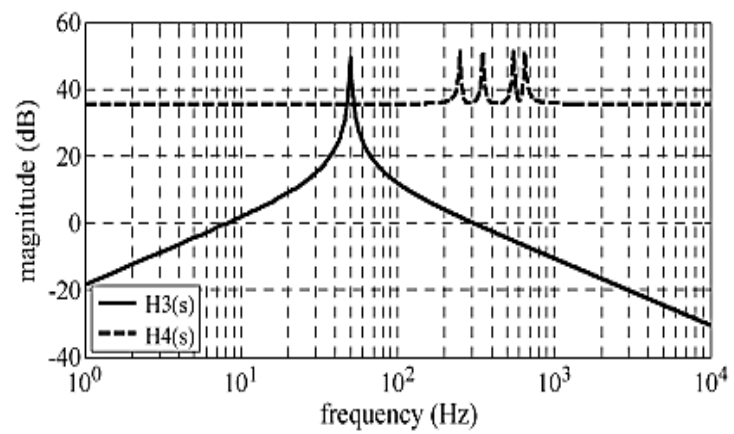

Fig. 4. Bode-Plot figure of PRES and RESH Controller used in Proposed Novel PRESH controller 
Bode-Plot of transfer function for proposed Novel PRESH controller is indicated by Fig. 5. All the value taken for case study of Novel PRESH controller is indicated in table 1.

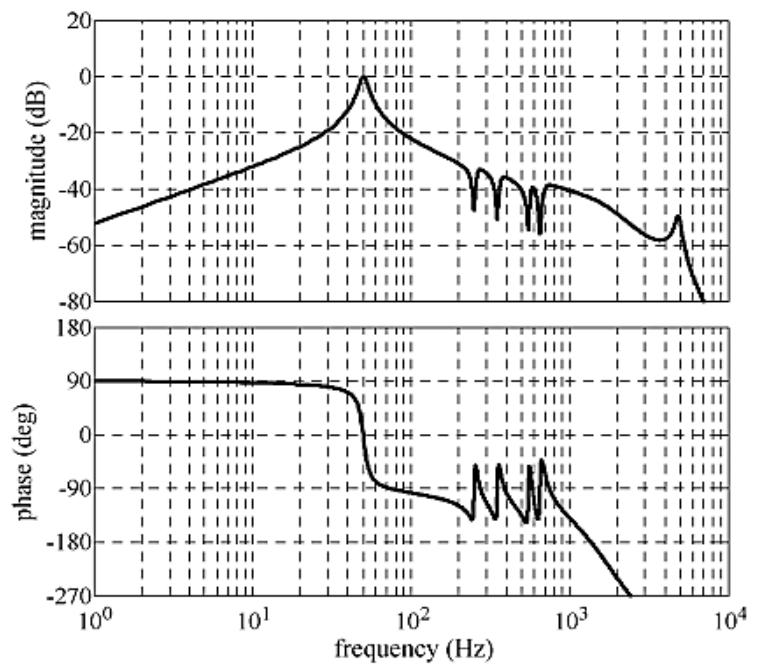

Fig. 5. Bode-Plot figure of proposed Novel PRESH controller

From the above figure it is clear that, transfer function of proposed Novel PRESH controller has behavior similar to band pass filter. At, selected harmonic frequency i.e 250, 350, 550 and $650 \mathrm{~Hz}$, dip in magnitude diagram can be seen. Thus, by using this proposed Novel PRESH controller, tracking of fundamental component of signal can be expected even if reference waveform is distorted one.

\section{B. Harmonic Analysis of proposed Novel PRESH Controller in three phase SPPS}

The proposed Novel PRESH Controller of this paper is tested with high voltage disturbances of the grid and the waveform of various parameter used is shown by Fig. 6 .

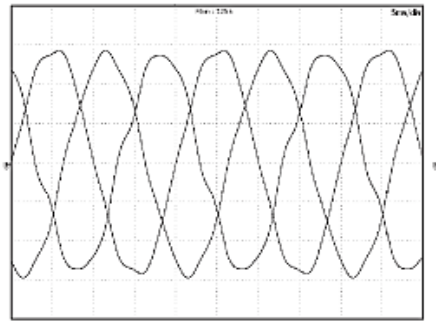

(a)

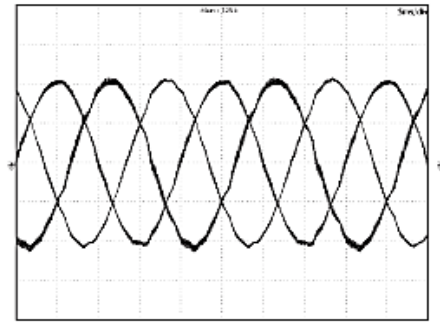

(c) (b)

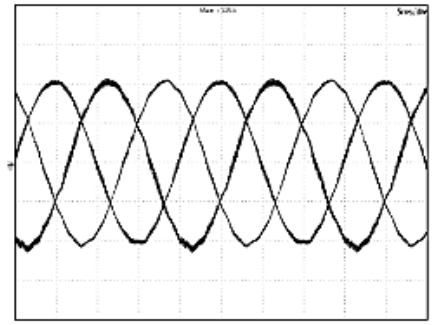

(d)

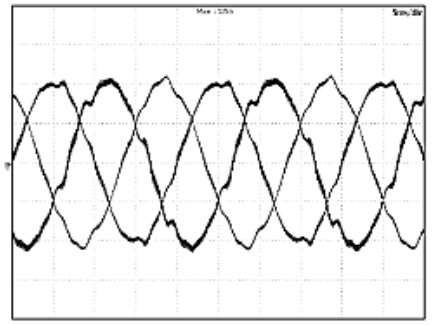

Fig. 6 Simulation result for grid condition with high voltage THD (a) Grid Voltage (b) Standard Control without Resonant Harmonic Controller (c) Standard Control with Resonant Harmonic Controller (d) Proposed Novel PRESH Controller

Harmonic distortion thus calculated is depicted by table 2 comparing the THD without controller and with proposed controller of the system.

Table 2 THD under different control technique

\begin{tabular}{|l|c|c|c|c|c|c|}
\hline Control Technique & $\mathbf{V}_{\mathbf{g a}}$ & $\mathbf{V}_{\mathbf{g b}}$ & $\mathbf{V}_{\mathbf{g c}}$ & $\mathbf{I}_{\mathbf{o a}}$ & $\mathbf{I}_{\mathbf{o b}}$ & $\mathbf{I}_{\mathbf{o c}}$ \\
\hline $\begin{array}{l}\text { Standard control without } \\
\text { Resonant Harmonic } \\
\text { Controller }\end{array}$ & 4.0 & 4.5 & 7.5 & 3.6 & 3.4 & 5.7 \\
\hline $\begin{array}{l}\text { Standard control with } \\
\text { Resonant Harmonic } \\
\text { Controller }\end{array}$ & 3,7 & 4.7 & 7.8 & 1.8 & 1.8 & 2.3 \\
\hline $\begin{array}{l}\text { Proposed Novel PRESH } \\
\text { Controller }\end{array}$ & 3.8 & 4.8 & 7.8 & 0.9 & 0.92 & 1.12 \\
\hline
\end{tabular}

From table 2, it is cleared that standard control gives very poor performance when resonant harmonic controller is not engaged however, the performance improves a bit after engaging the resonant harmonic controller.

The Proposed Novel PRESH controller reduces the current harmonic distortion well below to $5 \%$ which is as per IEEE standard 519 and 1547.

\section{CONCLUSION}

The presented paper discuss the design algorithm and performance analysis in term of THD and harmonic mitigation along with bode plot analysis of Novel PRESH (PRES+RESH) controller Interfaced with three phase SPPS (Solar Photovoltaic Power System).

Proposed Novel PRESH Controller was also tested with high voltage disturbances of the grid and waveform shows good result.

Further, identification of indirect mechanism is done that was responsible in generating the current harmonic from abnormal 
grid condition in standard resonant current controller

\section{ACKNOWLEDGMENT}

The work written is entirely original, acknowledge all sources of data and appropriately represent the work or words of others in citations or quotations.

\section{References}

[1] E. Figueres, G. Garcerá, J. Sandia, F. González-Espin, and J. C. Rubio, "Sensitivity study of the dynamics of three-phase photovoltaic inverters with an LCL grid filter," IEEE Trans. Ind. Electron., vol. 56, no. 3, pp. 706717, Mar. 2009.

[2] M. C. Cavalcanti, K. C. de Oliveira, A. M. de Farias, F. A. Neves, G. M. Azevedo, and F. C. Camboim, "Modulation techniques to eliminate leakage currents in transformerless three-phase photovoltaic systems," IEEE Trans. Ind. Electron., vol. 57, no. 4, pp. 1360-1368, Apr. 2010.

[3] M. Cacciato, A. Consoli, R. Attanasio, and F. Gennaro, "Soft-switching converter with HF transformer for gridconnected photovoltaic systems," IEEE Trans. Ind. Electron., vol. 57, no. 5, pp. 1678-1686, May 2010.

[4] S. V. Araujo, P. Zacharias, and R. Mallwitz, "Highly efficient single-phase transformerless inverters for gridconnected photovoltaic systems," IEEE Trans. Ind. Electron., vol. 57, no. 9, pp. 3118-3128, Sep. 2010.

[5] R. Kadri, J. P. Gaubert, and G. Champenois, "An improved maximum power point tracking for photovoltaic grid-connected inverter based-on voltage oriented control," IEEE Trans. Ind. Electron., vol. 58, no. 1, pp. 66-75, Jan. 2011.

[6] A. I. Bratcu, I. Munteanu, S. Bacha, D. Picault, and B. Raison, "Cascaded dc-dc converter photovoltaic systems: Power optimization issues," IEEE Trans. Ind. Electron., vol. 58, no. 2, pp. 403-411, Feb. 2011.

[7] Q. Mai, M. Shan, L. Liu, and J. M. Guerrero, "A novel improved variable step-size incremental-resistance MPPT method for PV systems," IEEE Trans. Ind. Electron., vol. 58, no. 6, pp. 2427-2434, Jun. 2011.

[8] N. A. Rahim, K. Chaniago, and J. Selvaraj, "Single-phase sevenlevel grid-connected inverter for photovoltaic system," IEEE Trans. Ind. Electron., vol. 58, no. 6, pp. 2435-2443, Jun. 2011.

[9] I. J. Balaguer, Q. Lei, S. Yang, U. Supatti, and F. Z. Peng, "Control for grid-connected and intentional islanding operations of distributed power generation," IEEE Trans. Ind. Electron., vol. 58, no. 1, pp. 147-157, Jan. 2011.

[10] J. M. Guerrero, J. C. Vasquez, J. Matas, L. Garcia de Vicuna, and M. Castilla, "Hierarchical control of droopcontrolled ac and dc microgrids - A general approach toward standardization," IEEE Trans. Ind. Electron., vol. 58, no. 1, pp. 158-172, Jan. 2011.

[11]C. Yuen, A. Oudalov, and A. Timbus, "The provision of frequency control reserves from multiple microgrids," IEEE Trans. Ind. Electron., vol. 58, no. 1, pp. 173-183, Jan. 2011.

[12] Characteristics of the Utility Interface for Photovoltaic (PV) Systems, IEC61727, Dec. 2004.

[13] IEEE Standard for Interconnecting Distributed Resources With Electric Power Systems, IEEE15471, 2008.

[14]2002 National Electrical Code, Nat. Fire Protection Assoc., Inc., Quincy, MA, 2002.

[15] Thomas Basso and N. Richard Friedman (November 2003) IEEE 1547 National Standard for Interconnecting Distributed Generation: How Could It Help My Facility?
[16]D. Shetty e N. Prabhu, "Ziegler-Nichols method based VAR current controller for static compensator", Energy Procedia, vol. 117, p. 543- 550, jun. 2017.

[17] M. T. Faiz, M. M. Khan, X. Jianming, S. Habib, e H. Tang, "Double feed-forward compensation based true damping of Inductor-capacitor-Induxtor type grid tied lainverter", in 2018 IEEE International Conference on Industrial Technology (ICIT), 2018, p. 788-793.

[18] Y. S. Kuo, J. Y. Lin, J. C. Tang, e J. G. Hsieh, "Lead-lag compensator design based on vector margin and steadystate error of the step response via particle swarm optimization", in 2016 International Conference on Fuzzy Theory and Its Applications (iFuzzy), 2016, p. 1-6.

[19]L. Wang, N. Ertugrul, e M. Kolhe, "Evaluation of died beat CC for grid tied converters", in IEEE PES Innovative Smart Grid Technologies, 2012, p. 1-7.

[20] J. N. da Silva, A. J. S. Filho, D. A. Fernandes, A. P. N. Tahim, E. R. C. da Silva, e F. F. Costa, "A discrete current controller for 1-phase grid-tied inverters", in 2017 Brazilian Power Electronics Conference (COBEP), 2017, p. $1-6$.

[21]K. Zhou, F. Blaabjerg, D. Wang, e Y. Yang, Periodic Control of PEC, IET, 2016.

[22] M. Castilla, J. Miret, J. Matas, L. Garcia de Vicuna, and J. M. Guerrero, "Control design guidelines for single-phase grid-connected photovoltaic inverters with damped resonant harmonics compensators," IEEE Trans. Ind. Electron., vol. 56, no. 11, pp. 4492-4501, Nov. 2009.

[23] M. Liserre, R. Teodorescu, and F. Blaabjerg, "Stability of photovoltaic and wind turbine grid-connected inverters for a large set of grid impedance values," IEEE Trans. Power Electron., vol. 21, no. 1, pp. 263-272, Jan. 2006.

[24]F. Blaabjerg, R. Teodorescu, M. Liserre, and A. V. Timbus, "Overview of control and grid synchronization for distributed power generation systems," IEEE Trans. Ind. Electron., vol. 53, no. 5, pp. 1398-1409, Oct. 2006.

[25] Yadav U., Gupta A., Rai H.K., Bhalla D.K (2021) Mitigation of Harmonic Current in Grid Connected Solar Power System. In: Muzammil M., Chandra A., Kankar P.K, Kumar H. (eds) Recent Advances in Mechanical Engineering. Lecture Notes in Mechanical Engineering. Springer, Singapore.

[26] P. Salmeron and S. Litran, "Improvement of the Electric Power Quality Using Series Active and Shunt Passive Filters," IEEE Transactions on Power Delivery, vol. 25, no. 2, pp. 1058-1067, 2010.

[27]Q. Trinh and H. Lee, "An Advanced Current Control Strategy for Three-Phase Shunt Active Power Filters," IEEE Transactions on Industrial Electronics, vol. 60, no. 12, pp. 5400-5410, 2013

[28] Jinwei He, Yun Wei Li, F. Blaabjerg and Xiongfei Wang, "Active Harmonic Filtering Using Current-Controlled, Grid-Connected DG Units with Closed-Loop Power Control," IEEE Transaction.

[29] L. B. G. Campanhol, S. A. O. Silva, L. P. Sampaio, A. A O. Junior, "A Grid-Connected Photovoltaic Power System with Active Power Injection, Reactive Power Compensation and Harmonic Filtering," in Proc. of COBEP, pp.642-649, 2013.

[30] U. Yadav and A. Gupta, "Current Harmonic Mitigation in Grid Tied Solar photovoltaic System via PRES" $20205^{\text {th }}$ IEEE International Conference on Recent Advances and Innovations in Engineering (ICRAIE), Jaipur, India, 2020, pp. 1-5.

[31]U. Yadav, A. Gupta and R. Ahuja, "Robust Control Design Procedure and Simulation of PRES Controller having phase-Locked Loop (PLL) control technique in Grid-Tied Converter" $20203^{\text {rd }}$ International Seminar on Research of Information Technology and Intelligent Systems (ISRITI) yogakarta, Indonesia, 2020, pp. 445450 . 
[32] A. S. Padula, E. J. Agnoletto, R. V. A. Neves, R. F. Q. Magossi, R. Q. Machado and V. A. Oliveira, "Partial Harmonic Current Distortion Mitigation in Microgrids Using Proportional Resonant Controller," 2019 18th European Control Conference (ECC), Naples, Italy, 2019, pp. 435-440.

[33] Althobaiti, M. Armstrong, M. A. Elgendy and F. Mulolani, "Three-phase grid connected PV inverters using the proportional resonance controller," 2016 IEEE 16th International Conference on Environment and Electrical Engineering (EEEIC), Florence, Italy, 2016, pp. 1-6.

[34] P. S. Prasad and A. M. Parimi, "Harmonic Mitigation in Grid Connected and Islanded Microgrid Via Adaptive Virtual Impedance," 2020 IEEE International Conference on Power Electronics, Smart Grid and Renewable Energy (PESGRE2020), Cochin, India, 2020, pp. 1-6.

[35] Jeong, H.-G.; Kim, G.-S.; Lee, K.-B. Second-Order Harmonic Reduction Technique for Photovoltaic Power Conditioning Systems Using a Proportional-Resonant Controller. Energies 2013, 6, 79-96.

[36] I. Etxeberria-Otadui, U. Viscarret, M. Caballero, A. Rufer, and S. Bacha, "New optimized PWM VSC control structures converter under unbalanced input voltage transients," IEEE Trans. Ind. Electron., vol. 54, no. 5, pp. 2902-2914, Oct. 2007.

[37] P. Rodríguez, J. Pou, J. Bergas, J. I. Candela, R. P. Burgos, and D. Boroyevich, "Decoupled double synchronous reference frame PLL for power converters control," IEEE Trans. Power Electron., vol. 22, no. 2, pp. 584-592, Mar. 2007.

[38]F. Wang, J. L. Duarte, and M. A. Hendrix, "Pliant active and reactive power control for grid-interactive converters under unbalanced voltage dips," IEEE Trans. Power Electron., vol. 26, no. 5, pp. 1511-1521, May 2011.

[39] P. Rodriguez, A. V. Timbus, R. Teodorescu, M. Liserre, and F. Blaabjerg, "Flexible active power control of distributed power generation systems during grid faults," IEEE Trans. Ind. Electron., vol. 54, no. 5, pp. 25832592, Oct. 2007.

[40] P. Rodriguez, A. V. Timbus, R. Teodorescu, M. Liserre, and F. Blaabjerg, "Reactive power control for improving wind turbine system behavior under grid faults," IEEE Trans. Power Electron., vol. 24, no. 7, pp. 1798- 1801, Jul. 2009.

[41] P. Rodriguez, A. Luna, I. Candela, R. Mujal, R. Teodorescu, and F. Blaabjerg, "Multiresonant frequencylocked loop for grid synchronization of power converters under distorted grid condition.

[42] M. Castilla, J. Miret, J. Matas, L. Garcia de Vicuna, and J. M. Guerrero, "Linear current control scheme with series resonant harmonic compensator for single-phase gridconnected photovoltaic inverters," IEEE Trans. Ind. Electron., vol. 55, no. 7, pp. 2724-2733, Jul. 2008.

[43] J. Miret, M. Castilla, J. Matas, J. M. Guerrero, and J. C. Vasquez, "Selective harmonic-compensation control for single-phase active power filter with high harmonic rejection," IEEE Trans. Ind. Electron., vol. 56, no. 8, pp. 3117-3127, Aug. 2009.

[44] A. G. Yepes, F. D. Freijedo, J. Doval-Gandoy, O. Lopez, J. Malvar, and P. Fernandez-Comesana, "Effects of discretization methods on the performance of resonant controllers," IEEE Trans. Power Electron., vol. 25, no. 7, pp. 1692-1712, Jul. 2010.

\section{Creative Commons Attribution License 4.0 (Attribution 4.0 International, CC BY 4.0)}

This article is published under the terms of the Creative Commons Attribution License 4.0 https://creativecommons.org/licenses/by/4.0/deed.en_US 